\title{
ANATOMIA DO LENHO DE TRÊS ESPÉCIES EXÓTICAS DO GÊNERO VACHELLIA WIGHT \& ARN. ${ }^{1}$
}

\author{
PAULO FERNANDO DOS SANTOS MACHADO² JOSÉ NEWTON CARDOSO MARCHIORI ${ }^{3}$ \\ ANELISE MARTA SIEGLOCH ${ }^{4}$
}

\section{RESUMO}

São anatomicamente descritas e ilustradas as madeiras de Vachellia collinsii (Saff.) Seigler \& Ebinger, Vachellia nilotica (L.) P.J.H. Hurter \& Mabb. e Vachellia planifrons (Wight \& Arn.) Ragup., Seigler, Ebinger \& Maslin. A estrutura observada nas três espécies corresponde ao padrão descrito para o gênero Vachellia Wight \& Arn., destacando-se a ausência de fibras septadas. Raios com 6 ou mais células de largura e a presença de cristais com mais de $60 \mu \mathrm{m}$, aspectos geralmente referidos para o gênero, foram observados em Vachellia nilotica e V. planifrons, mas não em V. collinsii. A ocorrência de parênquima axial abundante, por sua vez, foi registrada para V. planifrons, mas não para $V$. collinsii e V. nilotica.

Palavras-chave: Anatomia da madeira, Fabaceae, Vachellia Wight \& Arn., Vachellia collinsii, Vachellia nilotica, Vachellia planifrons.

\begin{abstract}
[Wood anatomy of three exotic species of genus Vachellia Wight \& Arn.].

The woods of Vachellia collinsii (Saff.) Seigler \& Ebinger, Vachellia nilotica (L.) P.J.H. Hurter \& Mabb., and Vachellia planifrons (Wight \& Arn.) Ragup., Seigler, Ebinger \& Maslin are anatomically described and illustrated. The structure observed in three species matches the pattern described for genus Vachellia Wight $\&$ Arn., highlighting the absence of septate fibers. Rays with 6 or more cells wide and the presence of crystals with more than $60 \mu \mathrm{m}$, features generally referred to the same genus, were observed in Vachellia nilotica and $V$. planifrons but not in $V$. collinsii. The occurrence of abundant axial parenchyma, in turn, was recorded to Vachellia planifrons, but not for $V$. collinsii and V. nilotica.
\end{abstract}

Key words: Wood anatomy, Fabaceae, Vachellia Wight \& Arn., Vachellia collinsii, Vachellia nilotica, Vachellia planifrons.

\section{INTRODUÇÃO}

Até seu desmembramento, Acacia Mill. (Fabaceae) era gênero de distribuição cosmopolita, reunindo cerca de 1.450 espécies lenhosas (Burkart, 1979), em sua maioria da

1 Recebido em 30-11-2014 e aceito para publicação em 20-03-2015.

2 Mestrando do Programa de Pós-Graduação em Engenharia Florestal. Bolsista CNPq. Universidade Federal de Santa Maria. Santa Maria, RS, Brasil. barcasole@gmail.com

3 Engenheiro Florestal, Dr. Bolsista de Produtividade em Pesquisa (CNPq - Brasil). Professor Titular do Departamento de Ciências Florestais, Universidade Federal de Santa Maria. Santa Maria, RS, Brasil.

4 Doutoranda do Programa de Pós-Graduação em Engenharia Florestal. Bolsista - CAPES. Universidade Federal de Santa Maria. Santa Maria, RS, Brasil.
Austrália (Rico-Arce, 2007). Em 2005, o Congresso Internacional de Botânica endossou a proposta de Orchard \& Maslin (2003), reservando o nome do antigo gênero para o grupo mais numeroso, correspondente à série Phyllodinae de George Bentham, o que implicou na transferência da espécie-tipo da africana Acacia nilotica (L.) Delile (atual Vachellia nilotica (L.) P.J.H. Hurter \& Mabb.) para a australiana Acacia penninervis Sieber ex DC. (McNeil et al., 2005). No caso das espécies americanas, elas foram transferidas, em sua maioria, para os gêneros Vachellia Wight \& Arn. e Senegalia Raf.

O gênero Vachellia abrange as antigas acácias do subgênero Acacia (ou série Gum- 
miferae, de Bentham), reunindo umas 159 espécies, nas três Américas (Rico-Arce, 2007), além de numerosos binômios da África, Índia e sete da Austrália (Maslin et al., 2003). No presente trabalho são investigadas três espécies exóticas desse gênero botânico no tocante à anatomia do lenho: Vachellia collinsii (Saff.) Seigler \& Ebinger, Vachellia nilotica (L.) P.J.H. Hurter \& Mabb. e Vachellia planifrons (Wight \& Arn.) Ragup., Siegler, Ebinger \& Maslin.

Arbusto ou árvore de até $5 \mathrm{~m}$ de altura, Vachellia collinsii (Saff.) Seigler \& Ebinger integra a sucessão secundária de ecossistemas sazonalmente secos da América Central, apresentando relação simbiótica com várias espécies de formigas (Rico-Arce, 2007). Provida de espinhos retos e ocos, a espécie, por vezes, é referida como Acacia collinsii Saff., binômio atualmente reduzido à sinonímia.

Antiga espécie-tipo do gênero Acacia Mill., Vachellia nilotica (L.) P.J.H. Hurter \& Mabb. é árvore nativa na África e Ásia, até a Índia, sendo cultivada na China, Austrália e nos trópicos do Novo Mundo, por ser uma das mais promissoras em zonas áridas (Rico-Arce, 2007). Além de madeira de boa qualidade, é a espécie produtora da "goma-arábica".

Conhecida, popularmente, como "umbrella thorn", Vachellia planifrons (Wight \& Arn.) Ragup., Siegler, Ebinger \& Maslin (antiga Acacia planifrons Wight \& Arn.) é árvore perenifólia, de copa plana e em formato de sombrinha, nativa no oeste do subcontinente indiano e em Sri Lanka (Kumar \& Sane, 2003). De crescimento lento, fornece madeira dura, pesada, indicada para implementos agrícolas ou como lenha (Sanjappa, 1992).

No tocante à anatomia da madeira, a literatura disponível ainda é escassa, face à importância econômica e o grande número de espécies do antigo gênero Acacia Mill. Entre outros caracteres anatômicos, Cozzo (1951) e Metcalfe \& Chalk (1972) relacionam para o mesmo: elementos vasculares curtos; pontoações inter- vasculares alternas, ornamentadas e de diâmetro pequeno a médio; placas de perfuração simples; parênquima paratraqueal; raios de células procumbentes; fibras libriformes; e ausência de estratificação.

Com relação ao lenho de espécies brasileiras de Vachellia Wight \& Arn., foram anatomicamente descritas até o presente momento: Vachellia caven (Mol.) Seigler \& Ebinger (Marchiori, 1980, 1990, 1992; Marchiori et al., 2009; Tortorelli, 1956), Vachellia farnesiana (L.) Wight \& Arn. (Marchiori, 1990, 2010) e Vachellia ibirocayensis (Marchiori) Deble \& Marchiori (Marchiori, 1990, 1993). A respeito da estrutura do lenho, Marchiori \& Santos (2011) concluíram que as mesmas compõem um grupo anatomicamente distinto de Senegalia Raf. e de Acacia Mill., por reunirem fibras não septadas e parênquima axial abundante, com séries de 2 (no máximo 3) células de altura. Os autores destacam, ainda, que Vachellia caven e $V$. farnesiana separam-se das demais espécies do antigo gênero Acacia Mill. pela alta percentagem de raios com mais de quatro células de largura, inclusive pela presença de raios conspícuos. Foi com base neste caráter anatômico, aliás, que Robbertse et al. (1980) distinguiram o antigo subgênero Acacia (atual gênero Vachellia) do subgênero Aculeiferum (atual gênero Senegalia).

O presente trabalho, além de descrever a estrutura do lenho de três espécies exóticas de Vachellia Wight \& Arn., visa, especialmente, a analisar o valor diagnóstico dos caracteres anatômicos apontados na literatura como característicos desse gênero botânico.

\section{MATERIAIS E MÉTODOS}

As amostras investigadas foram obtidas por doação de distintas instituições e foram incorporadas à Xiloteca do Herbário do Departamento de Ciências Florestais (HDCF) da Universidade Federal de Santa Maria com os seguintes registros: 
- Vachellia collinsii: IPT $\mathrm{n}^{\circ} 17.267$, cornizuelo (nome comum), Lab. de Productos Forestales, Costa Rica (procedência), sob o nome de "Acacia costarricensis". - Vachellia nilotica: IPT $\mathrm{n}^{\mathrm{o}} 5.887$, sob o nome de Acacia arabica.

- Vachellia planifrons: BFA no 15.981, Índia (procedência), sob o nome de Acacia planifrons Wight \& Arn.

Para a confecção de lâminas histológicas foram extraídos três corpos-de-prova (1 x2x3 $\mathrm{cm})$ de cada uma das amostras, orientados para a obtenção de cortes anatômicos nos planos transversal, longitudinal radial e longitudinal tangencial; um quarto bloquinho foi também preparado, com vistas à maceração.

A confecção das lâminas permanentes seguiu a metodologia descrita em Burger \& Richter (1991). No preparo de lâminas de macerado seguiu-se o método de Jeffrey (Freund, 1970). As secções anatômicas foram tingidas com acridina-vermelha, crisoidina e azul-de-astra (Dujardin, 1964); o macerado, apenas com safranina $1 \%$. Na montagem das lâminas permanentes usou-se Entellan.

As descrições basearam-se nas recomendações da IAWA (Wheeler et al., 1989). No caso da percentagem dos tecidos foram realizadas 600 determinações ao acaso, com auxílio de contador de laboratório, conforme proposto por Marchiori (1980). A frequência de poros foi obtida a partir de um quadrado de área conhecida, superposto a fotomicrografias de seções transversais da madeira.

As medições da estrutura anatômica foram realizadas em microscópio Carl Zeiss, no Laboratório de Anatomia da Madeira da Universidade Federal de Santa Maria. As fotomicrografias foram tomadas em microscópio Leica DM 1000, equipado com câmera digital Olympus Camedia CX-40, no Laboratório de Anatomia do Centro de Educação Superior Norte do Rio Grande do Sul (CESNORS - UFSM), em Frederico Westphalen, RS. Nas característi- cas quantitativas, os números entre parênteses equivalem aos valores mínimos e máximos observados; o valor que acompanha a média é o desvio padrão.

\section{DESCRIÇÃO ANATÔMICA}

Os caracteres anatômicos das três espécies em estudo são a seguir descritos e ilustrados.

\section{Vachellia collinsii (Saff.) Seigler \& Ebinger}

Anéis de crescimento: pouco distintos, delimitados por delgada camada de fibras e/ou parênquima radialmente achatadas, por tênue redução dos poros e ligeiro engrossamento dos raios (Figura 1A,B).

Vasos: pouco numerosos $(6,5 \pm 1,4(5-9)$ poros $/ \mathrm{mm}^{2}$ ), ocupando $15,2 \pm 3,8 \%$ do volume da madeira. Porosidade difusa. Poros solitários (51\%), em múltiplos radiais de 2-6 (40\%), e em múltiplos racemiformes de 3-10 (9\%); circulares ou ovais $(159 \pm 48(42-217) \mu \mathrm{m})$ e de paredes finas a espessas $(9,3 \pm 2,9(3,7-16,2)$ $\mu \mathrm{m})$ (Figura 1A,B). Elementos vasculares curtos $(297 \pm 74(100-480) \mu \mathrm{m})$, com placas de perfuração simples, oblíquas ou transversais ao vaso; apêndices curtos (41,6 $\pm 24,1(20-100)$ $\mu \mathrm{m})$, geralmente em uma extremidade. Pontoações intervasculares pequenas, circulares $(5,3 \pm 0,6(4,1-6,2) \mu \mathrm{m})$, alternas, com abertura em fenda inclusa, ornamentada, por vezes coalescente (Figura 1C,D,F). Pontoações raiovasculares, semelhantes às intervasculares, mas menores $(4,7 \pm 0,6(3,6-5,2) \mu \mathrm{m})$. Espessamentos espiralados, ausentes. Conteúdos, presentes.

Parênquima axial: representando $17 \pm 3,6 \%$ do volume da madeira; em arranjo vasicêntrico confluente, aliforme, por vezes apotraqueal difuso. Conteúdos, pouco frequentes (Figura 1A,B). Células fusiformes, raras. Séries parenquimáticas de $361 \pm 32(305-427) \mu \mathrm{m}$ de altura, com 3,2 \pm 1,2 (2-7) células (Figura $1 \mathrm{D}, \mathrm{F})$. Cristais romboédricos abundantes, em séries de 2 - 21 câmaras (Figura 1C,E,F). 

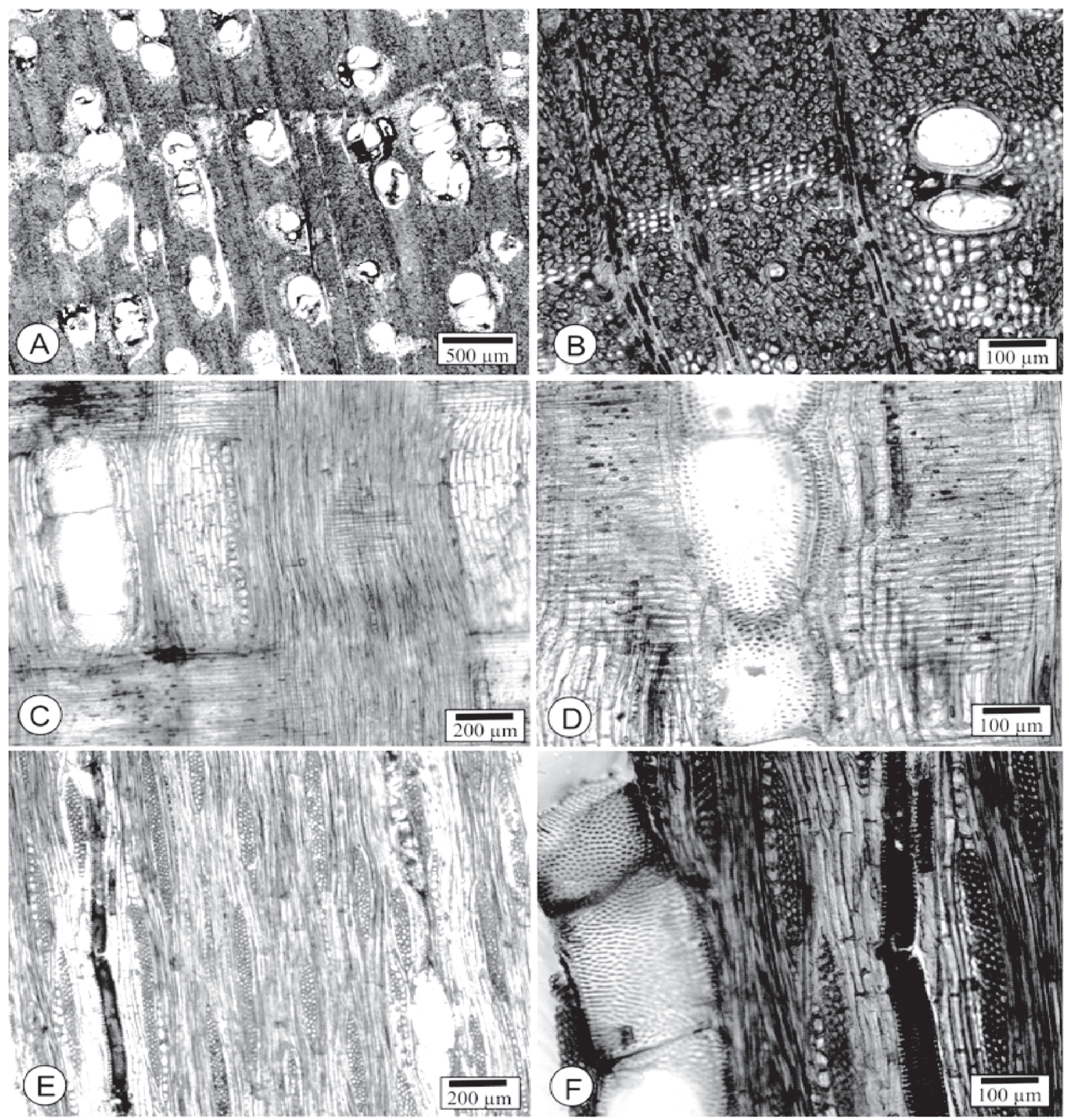

FIGURA 1 - Fotomicrografias do lenho de Vachellia collinsii. A - Porosidade difusa, poros solitários e em múltiplos radiais, limite do anel de crescimento e parênquima axial vasicêntrico, confluente e aliforme, por vezes apotraqueal difuso (seção transversal). B - Anel de crescimento delimitado por parênquima marginal e poros de diâmetro pequeno (seção transversal). C - Raios compostos inteiramente de células procumbentes, e parênquima axial seriado, com cristais (seção radial). D - Raio composto inteiramente de células procumbentes, elementos vasculares com placas de perfuração simples e pontoações intervasculares ornamentadas (seção radial). E - Raios multisseriados com 2 a 5 células de largura e parênquima axial com cristais (seção tangencial). E - Placas de perfuração transversais, pontoações intervasculares ornamentadas, raios tri a tetrasseriados, e parênquima axial com cristais (seção tangencial). 
Raios: numerosos (5 $\pm 0,8(4-7)$ raios $/ \mathrm{mm})$, representando $15 \pm 5 \%$ do volume da madeira; com $4(2-5)$ células e $38 \pm 5(28-50) \mu \mathrm{m}$ de largura; homogêneos, compostos inteiramente de células procumbentes (Figura 1E,F). Os multisseriados, de $336 \pm 178(120-730) \mu \mathrm{m} \mathrm{e}$ 9 - 71 células de altura. Os unisseriados, de 80 \pm 24 (40 - 140) $\mu \mathrm{m}$ e 3 - 11 células de altura. Conteúdos, cristais e raios agregados, presentes. Células envolventes, raios fusionados, células radiais de paredes disjuntas e células perfuradas, ausentes.

Fibras: libriformes, de $985 \pm 168(640-$ 1310) $\mu \mathrm{m}$ de comprimento, com $13,5 \pm 2,7$ (10 -20) $\mu \mathrm{m}$ de largura, e paredes finas a espessas $3,7 \pm 1,1(1,2-6,2) \mu \mathrm{m}$, ocupando $53 \pm 7,7 \%$ do volume da madeira (Figura 1A,B). Fibras gelatinosas, presentes; espessamentos espiralados, fibras septadas e traqueídeos, ausentes.

Outros caracteres: variantes cambiais, tubos laticíferos e taniníferos, canais intercelulares, células oleíferas, células mucilaginosas, estratificação e máculas medulares, ausentes. Cristais, presentes.

\section{Vachellia nilotica (L.) P.J.H. Hurter \& Mabb.}

Anéis de crescimento: pouco distintos, delimitados por delgada camada de fibras e/ou parênquima axial radialmente achatados, além de ligeiro alargamento de raios (Figura 2A,B).

Vasos: pouco numerosos $(7,3 \pm 0,9(6-8,5)$ poros $/ \mathrm{mm}^{2}$ ), ocupando $19 \pm 3,4 \%$ do volume da madeira. Poros solitários, em sua maioria (56\%), em múltiplos radiais de $2-14$ (35\%), menos comumente racemiformes (9\%); de seção circular ou oval $(144 \pm 40,1(40-240) \mu \mathrm{m})$ e paredes finas $(5,3 \pm 2,3(1,3-12,5) \mu \mathrm{m})(\mathrm{Fi}-$ gura 2A,B). Conteúdos, presentes (Figura 2A). Porosidade difusa (Figura 2A). Elementos vasculares curtos $(259 \pm 97,7(150-630) \mu \mathrm{m})$, com placas de perfuração simples, transversais ou oblíquas (Figura 2E,F); apêndices, curtos, em uma ou ambas as extremidades. Pontoações intervasculares de comprimento médio $(8 \pm 1,5$ $(5,1-9,3) \mu \mathrm{m})$, alternas, circulares ou poligonais, ornamentadas, com abertura em fenda inclusa, por vezes coalescente (Figura 2D,F). Pontoações raio-vasculares, semelhantes às intervasculares, embora menores $7 \pm 1(6,2-$ 9,3) $\mu \mathrm{m}$. Espessamentos espiralados, ausentes.

Parênquima axial: ocupando $11 \pm 2,3 \%$ do volume da madeira; comumente em arranjo unilateral, aliforme, vasicêntrico, por vezes vasicêntrico-confluente e paratraqueal-escasso (Figura 2A,B). Células fusiformes de $267 \pm 78$ $(118-475) \mu \mathrm{m}$ de altura. Séries parenquimáticas de $323 \pm 57$ (175 - 415) $\mu \mathrm{m}$ de altura, com 2,2 $\pm 0,5(2-4)$ células (Figura 2D). Cristais romboédricos abundantes, em até 27 câmaras por série.

Raios: numerosos (5 $\pm 1,7$ (4 - 9) raios $/ \mathrm{mm})$, ocupando $18 \pm 2,5 \%$ do volume da madeira, de $49 \pm 8(30-65) \mu \mathrm{m}$ e $1-6$ células de largura; homogêneos, compostos inteiramente de células procumbentes (Figura 2E,F). Os multisseriados, predominantes, de $470 \pm 142$ (190 730) $\mu \mathrm{m}$ e 12-48 células de altura (Figura 2C,D). Os unisseriados, de $94 \pm 17$ (60 - 140) $\mu \mathrm{m}$ e 4 - 10 células de altura. Células envolventes, células radiais de paredes disjuntas e células perfuradas, ausentes. Raios agregados e fusionados, presentes. Conteúdos, presentes.

Fibras: libriformes, de $866 \pm 340$ (290 1470) $\mu \mathrm{m}$ de comprimento, $14 \pm 2,6(10-20)$ $\mu \mathrm{m}$ de largura e paredes finas a espessas $3 \pm 0,8$ $(2,5-5) \mu \mathrm{m}$, ocupando $52 \pm 2,6 \%$ do volume da madeira (Figura 2A,B). Fibras gelatinosas, abundantes. Fibras septadas, espessamentos espiralados e traqueídeos, ausentes.

Outros caracteres: variantes cambiais, tubos laticíferos e taniníferos, canais intercelulares, células oleíferas, células mucilaginosas, estratificação e máculas medulares, ausentes. Cristais, presentes. 

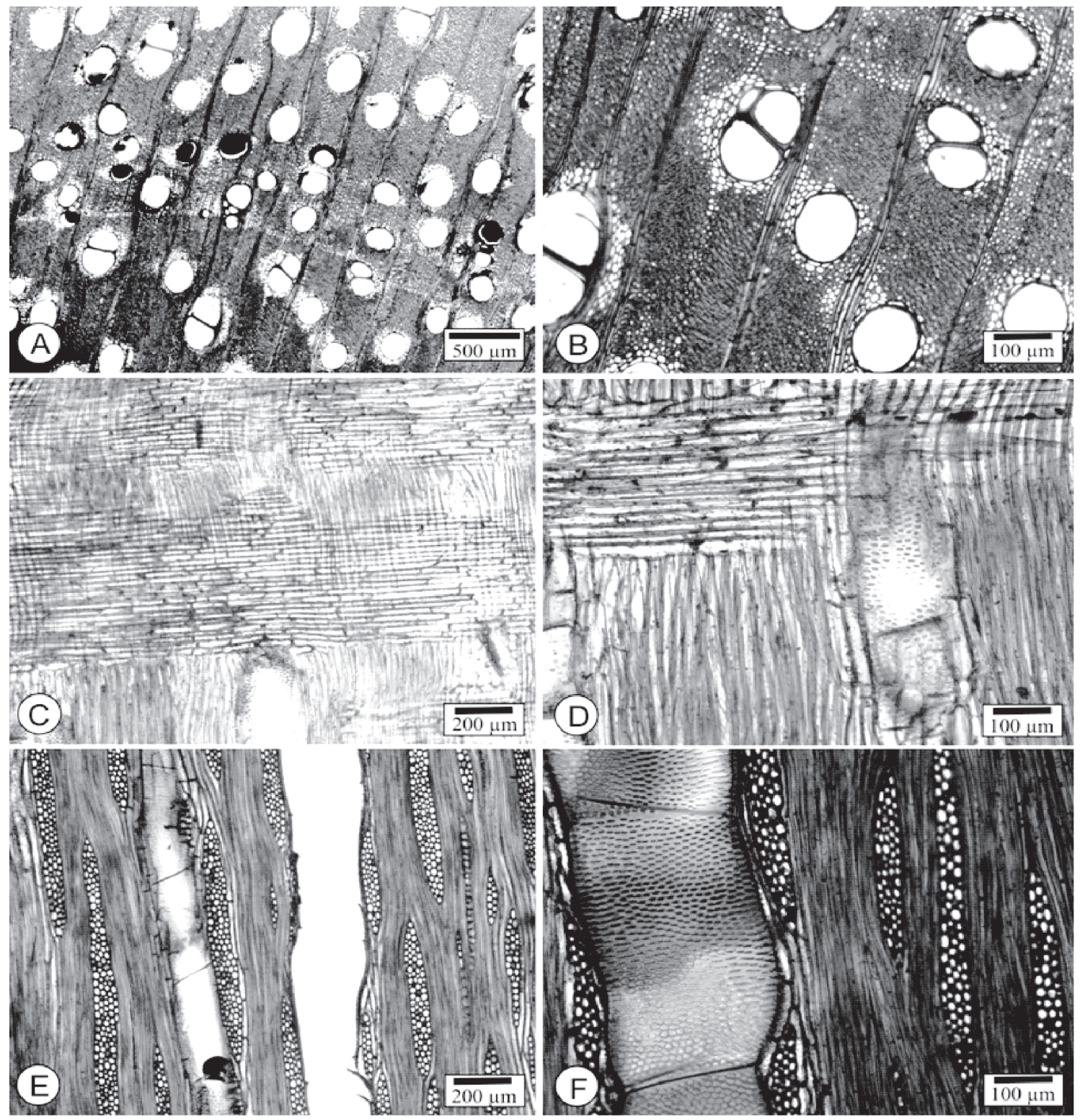

FIGURA 2 - Fotomicrografias do lenho de Vachellia nilotica. A - Porosidade semi-difusa, poros solitários e em curtos múltiplos radiais (com conteúdo), limite de anel delimitado por parênquima marginal e poros de menor diâmetro (seção transversal). B - Poros solitários e em curtos múltiplos radiais, parênquima paratraqueal e limite de anel de crescimento com parênquima marginal (seção transversal). C - Raios compostos inteiramente de células procumbentes (seção radial). D - Seção radial, em maior aumento, mostrando células procumbentes de raio e elemento vascular com pontoações alternas. E -Raios multisseriados e vasos (seção tangencial). F - Vaso com pontoações intervasculares alternas, por vezes coalescentes, placas de perfuração transversal e raios multisseriados (seção tangencial). 
Vachellia planifrons (Wight \& Arn.) Ragup., Seigler, Ebinger \& Maslin

Anéis de crescimento: pouco distintos, delimitados por delgada camada de fibras e/ou parênquima axial radialmente achatados, pela ligeira redução no diâmetro de poros e pelo tênue alargamento de raios (Figura 3A,B).

Vasos: escassos a pouco numerosos $(6,4 \pm$ $2,4(4-10)$ poros $\left./ \mathrm{mm}^{2}\right)$, ocupando $17 \pm 4,1 \%$ do volume da madeira. Porosidade difusa. Poros solitários (57\%), em múltiplos radiais de 25 (29\%), menos comumente racemiformes (14\%); circulares ou ovais $(114 \pm 33(47-167)$ $\mu \mathrm{m})$ e de paredes finas a espessas $(7,4 \pm 3(2,5$ -10) $\mu \mathrm{m})$ (Figura 3A,B). Elementos vasculares curtos $(273 \pm 63(170-400) \mu \mathrm{m})$, com placas de perfuração simples, oblíquas ou transversais ao vaso; apêndices curtos $(45,6 \pm 26(20-120)$ $\mu \mathrm{m})$, geralmente em uma extremidade. Pontoações intervasculares pequenas e arredondadas $(6,7 \pm 1,0(5,2-8,2) \mu \mathrm{m})$, alternas, com abertura em fenda inclusa, por vezes coalescente (Figura 3D). Pontoações raio-vasculares, semelhantes às intervasculares, embora menores (6 $\pm 0,8(5,2-7,2) \mu \mathrm{m})$. Espessamentos espiralados e conteúdos, ausentes.

Parênquima axial: abundante, representando $34 \pm 6,3 \%$ do volume da madeira; em arranjo paratraqueal confluente e em faixas com mais de três células de largura, por vezes aliforme e vasicêntrico. Conteúdos, ausentes (Figura $3 \mathrm{~A}, \mathrm{~B})$. Células fusiformes de $221 \pm 66$ (125 377) $\mu \mathrm{m}$ de altura. Séries parenquimáticas de $301 \pm 54(182-375) \mu \mathrm{m}$ e $2,2 \pm 0,4(2-3)$ células de altura (Figura 3D,F). Cristais romboédricos, extremamente abundantes, geralmente com mais de 30 cristais por série, compondo longas faixas axiais ou dispersas no tecido lenhoso.

Raios: pouco numerosos $(4 \pm 1,0(2-5)$ raios $/ \mathrm{mm}$ ), ocupando $13 \pm 2,4 \%$ do volume da madeira, com $6(2-10)$ células e $64 \pm 18$ (25 88) $\mu \mathrm{m}$ de largura; homogêneos, compostos inteiramente de células procumbentes (Figura
3E,F). Os multisseriados, de $519 \pm 203$ (250 1050) $\mu \mathrm{m}$ e 18 - 75 células de altura. Os unisseriados, de $112 \pm 58(30-300) \mu \mathrm{m}$ e $2-$ 20 células de altura. Conteúdos, ausentes. Células envolventes, raios fusionados, células radiais de paredes disjuntas, células perfuradas e raios agregados, ausentes. Cristais, presentes.

Fibras: libriformes, de comprimento médio $(1100 \pm 185(700-1430) \mu \mathrm{m})$, com $14 \pm 3(7,5$ $-17,5) \mu \mathrm{m}$ de largura e paredes finas a espessas $3,0 \pm 0,6(2,5-3,7) \mu \mathrm{m}$, ocupando $36 \pm 4,9 \%$ do volume da madeira (Figura 3A,B). Fibras gelatinosas, abundantes. Espessamentos espiralados, fibras septadas e traqueídeos, ausentes.

Outros caracteres: variantes cambiais, tubos laticíferos e taniníferos, canais intercelulares, células oleíferas, células mucilaginosas, estratificação e máculas medulares, ausentes. Cristais, presentes.

\section{ANÁLISE DA ESTRUTURAANATÔMICA}

Os principais caracteres anatômicos das espécies em estudo estão de acordo com o referido por Metcalfe \& Chalk (1972) para o antigo gênero Acacia Mill.: poros principalmente solitários, em pequenos múltiplos e cachos irregulares; porosidade semi-difusa; placas de perfuração simples; pontoações intervasculares ornamentadas, pequenas e alternas; elementos vasculares curtos; parênquima axial abundante, paratraqueal, ocasionalmente confluente ou em longas faixas irregulares, raramente conspícuo; cristais romboédricos, em câmaras no parênquima axial; raios homogêneos, com 1-9 (geralmente 2-5) células de largura ou exclusivamente unisseriados; e fibras libriformes moderadamente longas, septadas em alguns gêneros.

Os raios homogêneos, observados nas três espécies, são sugestivos da subfamília Mimosoideae, de acordo com Baretta-Kuipers (1980).

Os caracteres de valor diagnóstico usados para a diferenciação anatômica dos gêneros re- 

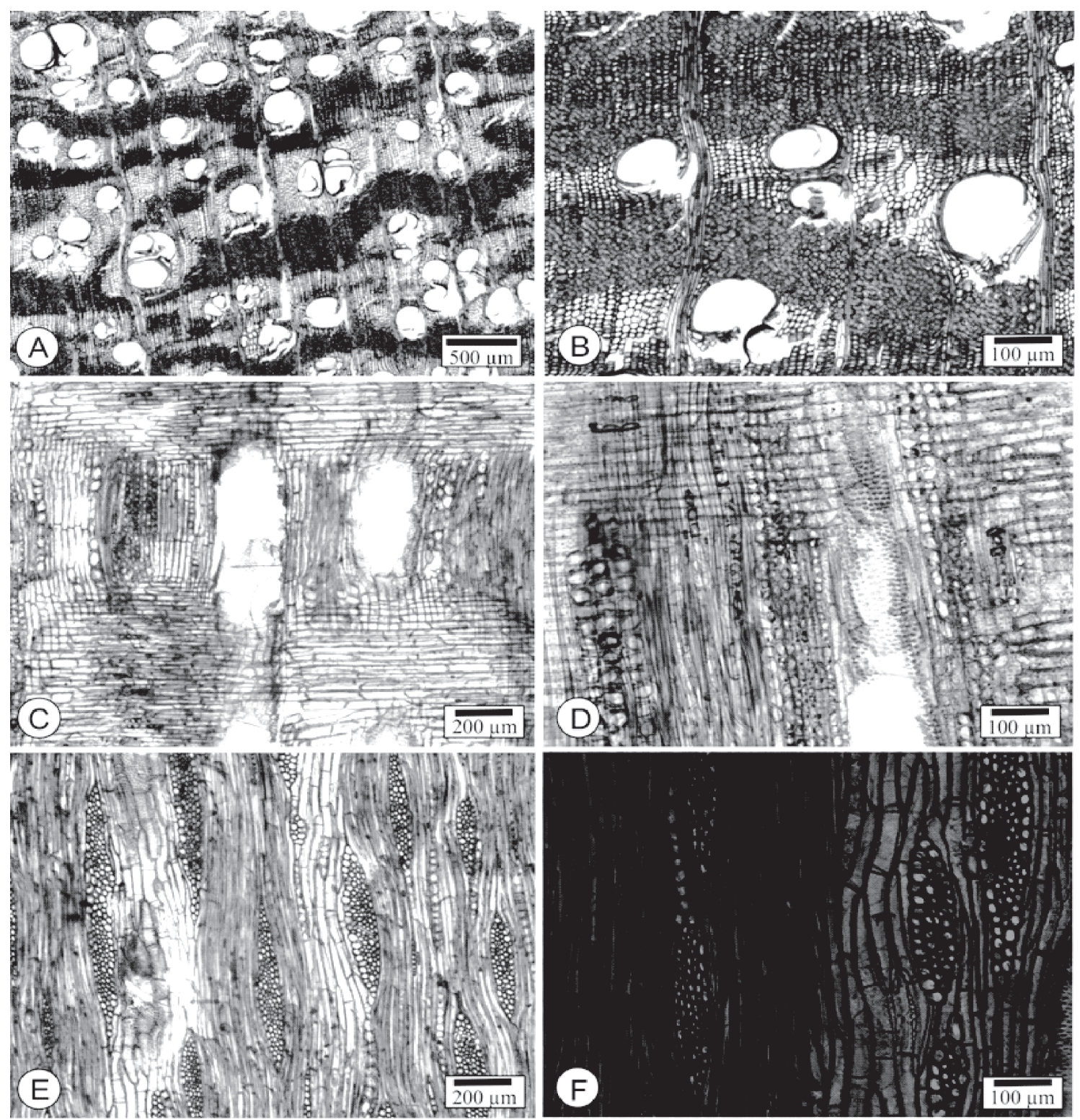

FIGURA 3 - Fotomicrografias do lenho de Vachellia planifrons. A - Seção transversal, mostrando porosidade semidifusa, poros solitários e em curtos múltiplos radiais, limite de anel marcado por parênquima marginal e parênquima paratraqueal em faixas. B - Mesma seção, evidenciando poros solitários, limite de anel de crescimento e abundante parênquima em faixas. C - Raios compostos inteiramente de células procumbentes e parênquima axial com abundantes séries cristalíferas. D - Seção radial, mostrando células procumbentes de raio, elemento vascular com pontoações alternas e abundantes séries cristalíferas no parênquima axial. E - Vista geral da seção tangencial, com destaque para raios multisseriados e faixas de parênquima axial. F - Raios multisseriados e faixas de parênquima axial (seção tangencial). 
TABELA 1 - Caracteres anatômicos de seis espécies do gênero Vachellia Wight \& Arn.

\begin{tabular}{l|l|l|l|l|l|l|l|l}
\hline Espécies & Fs & Fns & PAa & PAe & Re & RI & Cg & Cp \\
\hline Vachellia caven & & $\mathrm{X}$ & $\mathrm{X}$ & & & $\mathrm{X}$ & $\mathrm{X}$ & \\
\hline Vachellia collinsii & & $\mathrm{X}$ & & $\mathrm{X}$ & $\mathrm{X}$ & & & $\mathrm{X}$ \\
\hline Vachellia farnesiana & & $\mathrm{X}$ & $\mathrm{X}$ & & & $\mathrm{X}$ & $\mathrm{X}$ & \\
\hline Vachellia ibirocayensis & & $\mathrm{X}$ & $\mathrm{X}$ & & $\mathrm{X}$ & & & $\mathrm{X}$ \\
\hline Vachellia planifrons & & $\mathrm{X}$ & $\mathrm{X}$ & & & $\mathrm{X}$ & & $\mathrm{X}$ \\
\hline Vachellia nilotica & & $\mathrm{X}$ & & $\mathrm{X}$ & & $\mathrm{X}$ & & $\mathrm{X}$ \\
\hline
\end{tabular}

Onde: Fs $=$ Fibras septadas; Fns = Fibras não septadas; PAa $=$ Parênquima axial abundante $(>25 \%) ;$ PAe $=$ Parênquima axial escasso ( $<20 \%) ; \mathrm{Re}=$ Raios estreitos $(1-4$ - seriados); $\mathrm{R} 1=$ com raios largos ou conspícuos $(+$ de 6 células de largura); $\mathrm{Cg}=$ Cristais grandes $(>60 \mu \mathrm{m})$, presentes; $\mathrm{Cp}=$ cristais pequenos $(<$ $25 \mu \mathrm{m})$, apenas.

centemente segregados de Acacia Mill. são resumidos na Tabela 1, para seis espécies de Vachellia Wight \& Arn., incluindo as três em estudo.

A ausência de fibras septadas nas seis espécies da Tabela 1 está de acordo com Marchiori \& Santos (2011), que consideram o caráter de valor diagnóstico para o gênero Senegalia Raf.

A segregação anatômica dos gêneros Acacia Mill. e Vachellia Wight \& Arn., todavia, resulta mais complexa do que o afirmado por Marchiori \& Santos (2011). Embora abundante, o parênquima axial em Vachellia collinsii e Vachellia nilotica fica abaixo de $20 \%$, limite estabelecido por Marchiori \& Santos (2011) para a separação dos dois gêneros em foco. A ocorrência de raios largos ( $>6$ células), carácter citado por Robbertse et al. (1980) e Marchiori \& Santos (2011) como sugestivo de espécies do atual gênero Vachellia, também apresenta duas exceções na Tabela 1, nos casos de Vachellia collinsii e V. ibirocayensis, respectivamente. De todo modo pode-se afirmar que raios largos e parênquima axial abundante, geralmente com duas células por série, são aspectos sugestivos do gênero Vachellia Wight \& Arn., permitindo, quando reunidos numa mesma amostra de madeira, segregá-la do gênero Acacia Mill.

\section{REFERÊNCIAS BIBLIOGRÁFICAS}

BARETTA-KUIPERS, T. The wood structure of leguminous tribes: their characterization by ray and parenchyma features. For. Prod. Abstr., v. 3, n. 8, p. 1784, 1980. (Resumo).

BURGER, L.M.; RICHTER, H.G. Anatomia da Madeira. São Paulo: Ed. Nobel, 1991. 154 p.

BURKART, A. Leguminosas Mimosoideas. In: REITZ, R. Flora Ilustrada Catarinense. Itajaí: Herbário Barbosa Rodrigues, 1979. 229 p.

COZZO, D. Anatomia del leño secundario de las Leguminosas Mimosoideas y Caesalpinoideas silvestres y cultivadas. Rev. Inst. Nac. Invest. Ci. Nat. Ci. Bot., Buenos Aires, v. 2, n. 2, p. 63290, 1951.

DUJARDIN, E.P. Eine neue Holz-Zellulosenfaerbung. Mikrokosmos, n. 53, p. 94, 1964.

FREUND, H. Handbuch der Mikroskopie in der Technik. Frankfurt: Umsham Verlag, 1970.

KUMAR, S.; SANE, P.V. Legumes of South Asia: a checklist. Kew: Kew Publishing, 2003. 543 p.

LUCKOW, M. et. al. Acacia: the case against moving the type to Australia. Taxon, v.54, n.2, p. 513519, 2005.

MARCHIORI, J.N.C. Estudo anatômico do xilema secundário e da casca de algumas espécies dos gêneros Acacia e Mimosa, nativas no Estado do Rio Grande do Sul. Curitiba: UFPR, 1980. 185 f. Dissertação (Mestrado em Engenharia Florestal - Universidade Federal do Paraná). 
MARCHIORI, J.N.C. Anatomia das madeiras do gêenero Acacia, nativas e cultivadas no Rio Grande do Sul. Curitiba: UFPR, 1990. 226 f. Tese (Doutorado em Engenharia Florestal - Universidade Federal do Paraná).

MARCHIORI, J.N.C. Anatomia da madeira e casca do espinilho, Acacia caven (Mol.) Mol. Ciência Florestal, Santa Maria, v. 2, n. 1, p. 27-47, 1992.

MARCHIORI, J.N.C. Estudo antômico do xilema secundário de Acacia ibirocayensis Marchiori (Leguminosae Mimosoideae). Ciência e Natura, Santa Maria, n. 15, p. 149-159, 1993.

MARCHIORI, J.N.C.; MUÑIZ, G.I.B. de; SANTOS, S.R. dos. Madeiras do Rio Grande do Sul. 1 Descrição microscópica de 33 espécies nativas. Santa Maria: [s.n.], 2009. 80 p.

MARCHIORI, J.N.C. Anatomia da madeira de Vachellia farnesiana (L.) Wight \& Arn. Balduinia, Santa Maria, n. 22, p. 9-14, 2010.

MARCHIORI, J.N.C.; SANTOS, S.R. dos. A segregação do gênero Acacia (Tourn.) Mill., sob o ponto de vista da anatomia da madeira de espécies nativas e cultivadas no Rio Grande do Sul. Balduinia, n. 30, p. 25-36, 2011.

MASLIN, B.R.; MILLER, J.T.; SEIGLER, D.S. Overview of the generic status of Acacia (Leguminosae: Mimosoideae). Australian Systematic Botany, v. 16, p. 1-18, 2003.
McNEIL, J.; STUESSY, T.F.; TURLAND, N.J.; MÖRAND, E. XVII International Botanical Congress: preliminary mail vote and report of Congress action on nomenclature proposals. Taxon, v. 54, n. 4, p. 1057-1064, 2005.

METCALFE, C.R., CHALK, L. Anatomy of the Dicotyledons: leaves, stem, and wood in relation to Taxonomy with notes on economic uses. Oxford: Clarendon Press, 1950. 1500p.

ORCHARD, A.E.; MASLIN, B.R. Proposal to conserve the name Acacia (Leguminosae: Mimosoideae) with a conserved type. Taxon, v. 52, p. 362-363, 2003.

RICO-ARCE, M. de L. American species of Acacia. México: Comisión Nacional para el Conocimiento y Uso de la Biodiversidad (CONABIO), 2007. 207 p.

ROBBERTSE, P.J.; VENTER, G.; RENSBURG, H.J. The wood anatomy of the South African Acacias. IAWA Bulletin, v. 1, n. 3, p. 93-103, 1980.

SANJAPPA, M. Legumes of India. Dehra Dun: Bishen Singh Mahendra Pal Singh, 1992. 338p.

TORTORELLI, L.A. Maderas y bosques argentinos. Buenos Aires: ACME, 1956. 910 p.

WHEELER, E.A.; BAAS, P.; GASSON, P.E. IAWA list of microscopic features for hardwood identification. IAWA Bulletin, v.10, n. 3, p. 218359, 1989. 